\title{
Partnering with patients: how did you involve patients in your research?
}

\author{
Sandy Goldbeck-Wood, ${ }^{1,2}$ Toni Belfield ${ }^{3}$
}

${ }^{1}$ Editor-in-Chief, Journal of Family Planning and Reproductive Health Care, London, UK

${ }^{2}$ Clinical Lead for Abortion Services, Cambridge University Hospitals, Cambridge, UK ${ }^{3}$ Sexual Health Information Advisor, Journal of Family Planning and Reproductive Health Care, London, UK

\section{Correspondence to}

Dr Sandy Goldbeck-Wood, Journal of Family Planning and Reproductive Health Care, Faculty of Sexual \& Reproductive Healthcare, 27 Sussex Place, London NW1 4RG, UK; goldbeckwood@doctors.org.uk

Received 23 February 2017 Accepted 23 February 2017

\section{CrossMark}

To cite: Goldbeck-Wood S, Belfield T. J Fam Plann Reprod Health Care 2017;43:94-95.
With this journal issue, we are introducing a new requirement for authors of original research papers to tell us how they have involved patients, or service users, in the conception, design, conduction and interpretation of their research. We are doing this because we think it will help us publish better papers - meaning papers better able to improve clinical outcomes - and because we think it is the right thing to do. Involving patients in research is a step towards reducing bias and waste in research ${ }^{1}$ as well as the kind of injustice which arises when the views of relevant stakeholders are discounted or downgraded. ${ }^{2}$ We are not the first to take such an initiative - the $B M J$ has led the way with its Patient Partnership Strategy, a serious attempt to integrate patient perspectives into how we work and think in healthcare. ${ }^{3}$

Although patient-centredness is a core element in the mission of healthcare, paternalism has traditionally denied patients and the public influence in actually shaping services, or defining their value. ${ }^{4}$ Yet without the benefit of patient expertise, it is too easy for professionals to focus on key technical endpoints, such as increasing long-acting reversible contraception uptake, while overlooking other outcomes which patients value, such as autonomy, or those considered an unacceptable 'treatment burden', such as side effects affecting sexual or social function.

Many organisations across healthcare now recognise the need for change, and are developing their own patient partnership initiatives. ${ }^{5}{ }^{6}$ Last month, Organisation for Economic Co-operation and Development (OECD) health ministers committed to use patient reported indicators - so called Patient Reported Experience Measures (PREMs) and Patient Reported Outcome Measures
(PROMs) - to compare health system performance. ${ }^{7} 8$ Within research, organsiations such as National Institute for Health Research (NIHR) and Patient-Centered Outcomes Research Institute (PCORI) are developing their own patient partnership initiatives ${ }^{59}$, aimed at integrating patients as generators of research questions and relevant outcomes, as co-applicants on grants, critics of research methods, members of trial management and steering groups, and contributors to data analysis and written and oral dissemination of research results.

In developing our own thinking on this topic, we are especially indebted for inspiration and support to BMJ Patient Editor, Rosamund Snow, whose sudden death in February 2017 shocked and saddened us greatly. Her obituary on p. $170,{ }^{10}$ abridged from the $B M J^{11}$ and published with their kind permission, shows how effectively she has helped editors and authors to understand "what patient involvement really means".

Insisting on greater transparency at the point of publication about patient involvement in research is a step Rosamund firmly advocated. Its aim is to reduce bias in what we publish, thereby improving its quality and relevance. But as well as reducing scientific bias, it is aimed at correcting an equally important injustice - the kind which arises when the legitimate testimony of the most relevant stakeholders is discounted or downgraded and their status as 'knowers' denied - the kind which has been termed epistemic injustice. ${ }^{2}$

So to our future authors, we want to say thank you for joining us to deepen our own partnership with patients and service users. We know that the filling out of a single form will not change much on its own. We understand that including patients means much more 
than that, is hard to do well, and is fraught with the risk of tokenism, dilettantism, and the impossibility of achieving representativeness. But we do not want difficulty to be our excuse for doing nothing, and we hope that the journal's new requirements regarding patient involvement will help us think in new ways. Because, in Rosamund Snow's words: "patients can see things in research that clinicians can't, because we think to look in new places". ${ }^{12}$

Competing interests None declared.

Provenance and peer review Commissioned; internally peer reviewed.

\section{REFERENCES}

1 Chalmers I, Bracken MB, Djulbegovic B, et al. How to increase value and reduce waste when research priorities are set. The Lancet 2014;383:156-165.

2 Fricker M. Epistemic Injustice: Power and the Ethics of Knowing. New York, NY, USA: Oxford University Press, 2009:20.

3 Richards T, Godlee F. The BMJ's own patient journey. BMJ 2014;348:g3726.

4 Richards T, Coulter A, Wicks P. Time to deliver patient centred care. BMJ 2015;350:h530.

5 National Institute for Health Research (NIHR) Collaboration for Leadership in Applied Health Research and Care South
West Peninsula (PenCLAHRC). [A collaboration involving Exeter and Plymouth Universities and 13 NHS organisations.] http://clahrc-peninsula.nihr.ac.uk [accessed 20 February 2017].

6 Royal College of Obstetricians \& Gynaecologists (RCOG). RCOG Women's Network. https://www.rcog.org.uk/en/patients/ rcog-womens-network/ [accessed 20 February 2017].

7 Organisation for Economic Co-operation and Development. (OECD). Recommendations to OECD Ministers of Health from the High Level Reflection Group on the Future of Health Statistics. 2017. https://www.oecd.org/els/health-systems/ Recommendations-from-high-level-reflection-group-on-thefuture-of-health-statistics.pdf [accessed 20 February 2017].

8 Coulter A, Locock L, Ziebland S, et al. Collecting data on patient experience is not enough: they must be used to improve care. BMJ 2014;356:g2225. doi:10.1136/bmj.g2225 pmid:24671966

9 Patient-Centered Outcomes Research Institute (PCORI). PCORI Methodology Standards. http://www.pcori.org/ research-results/research-methodology/pcori-methodologystandards [accessed 20 February 2017].

10 Rosamund Snow: researcher and campaigner for patients' involvement in healthcare (Obituary). J Fam Plann Reprod Health Care 2017;43:170.

11 Payne D. Rosamund Snow - researcher and campaigner for patients' involvement in healthcare. BMJ 2017;346:j850.

12 Snow R. What makes a real patient? http://blogs.bmj.com/bmj/ 2016/07/19/rosamund-snow-what-makes-a-real-patient/ [accessed 20 February 2017]. 